\title{
EFFECT OF SALINITY ON GONAD DEVELOPMENT IN DIPLODUS VULGARIS (FAMILY: SPARIDAE) DURING THE BREEDING SEASON.
}

\section{Samia G. Moharram}

National Institute of Oceanography \& Fisheries, Alexandria. Egypt.

\section{(Received December 22, 1999)}

Key words: Salinity, gonadal development, Diplodus vulgaris, Sparidae, fish

\section{ABSTRACT}

$\mathrm{M}$ orphological and histological studies demonstrated that salinity affects gonadal development of Diplodus vulgaris. Fishes exposed to salinity $25 \%$ were characterized by reduction in the gonad size, GSI values and the testes seemed to be atrophied. Degeneration of both spermatogonia and oocytes were observed at this level of salinity. At $16 \%$ salinity, the gonads were slightly reduced in size, early ripening of males and early sex reversal were observed. By increasing salinity to $40 \%$, the gonad weight and GSI values were decreased. Inhibition of spermatogenesis in males, collapse of the oocytes and marked shrinkag in the nucleus diameter were detected. The ovaries of females showed some types of abnormalities: development of small vacuoles all over the cytoplasm which was not homogenous. It was observed that exposure to salinity $48 \%$ caused the most deleterious effect on the gonads. Hypertrophy followed by degeneration of spermatogonia and deformation of seminiferous lobules, cessation of cell division and deformation of the oocytes were observed.

\section{INTRODUCTION}

Sea bream (family: Sparidae) have wide distribution in the Mediterranean Sea (Tortonese, 1965). They are considered as an important commercial fishes in the Egyptian Mediterranean waters. 
Timing and success of teleost reproduction are directly or indirectly controlled by environmental factors which influence gonadal activity through the mediation of the hypothalamo-pituitary gonad axis which result in endocrine fluctuation (Crim, 1982).

The environmental factors such as photoperiod, temperature, salinity and stress are known to have clear influences on the reproductive activities of fishes (Ashan, 1966; de Vlaming, 1972; Breton and Billard, 1977; Lam, 1983; Bye, 1984 and Stacey, 1984).

Diplodus vulgaris is a hermaphrodite fish like other sparids. Sparid fishes exhibit a diverse sexuality (Atz, 1964 and Reinboth, 1970) which may be expressed as either sequential hermaphrodtism (protandry or protogyny) or "late" gonochorism (rudimentary hermaphroditism) (Buxton and Garratt, 1990). The expression of this sexuality is complex in many sparid species and its interpretation rather difficult (Matsuyama et al, 1988).

Reproductive studies done on several important and commercial sparid fish have shown that the majority of these species are either protogynous or rudimentary hermaphrodites (Buxton, 1990; Buxton and Clarke, 1991, 1992; and Bennett, 1993).

Previous researches on family Sparidae have focused on the reproductive biology and culture of some species of this family.

The aim of the present work is to gain an insight on the influence of salinity on the gonadal development of Diplodus vulgaris during natural breeding season.

\section{MATERIALS AND METHODS.}

Experiments were carried out in laboratory during the period from $14^{\text {th }}$ of October to the beginning of December 1998. 


\section{A-Fish sample:}

1-Fishes were collected from their natural habitat in the Egyptian Mediterranean water (off Alexandria) at the beginning of October and were stocked in experimental tanks.

Fishes were transferred to clyndrico-conical fiberglass tanks where water was maintained at ambient photoperiod, temperature and salinity for at least one week.

2-Four aquaria with different water salinities were used to carry out this experiment as shown in table (1). Salinities lower than the ambient salinity (36pt) were obtained by diluting seawater with dechloridated tap water. Salinities higher than ambient were obtained by adding concentrated brine solution to seawater which was prepared by dissolving sun dried seawater salt in seawater. Salinity was measured with a refractometer-salinometer once a day and oxygen once a week.

3-Maturity stages were classified according to Yamamoto (1956) and Guraya et,al. (1975) reviewed by west (1990). Ganado-somatic index (GSI) was calculated as:

$$
\mathrm{GSI}=\underline{\text { Gonad weight }}_{\text {Gutted weight }(\mathrm{g})}^{\text {Go }} \times 100
$$

\section{B-Histological study:}

For histological examination, sub-samples of gonadal tissues were fixed in Bouin's solution for three days and then stored in $70 \%$ ethyl alcohol, then dehydrated through ascending series of ethanol solution (50$100 \%$ ), cleared in methyl benzoate and embedded in paraffin wax. Sections were cut at five and seven $\mu \mathrm{m}$ thick for male and female respectively and stained with Ehrlich's haematoxylin and eosin. It must be noted that histological sex determination was only done for the fish that had reached approximately $14 \mathrm{~cm}$.total length. 


\section{RESULTS}

\section{I-Gonads under ambient salinity (control fish):}

For understanding the changes that occurred during this experiment, a brief description of Diplodus vulgaris gonads taken by the end of November from the control tank is given as follows:

Macroscopically the male's gonads had smooth texture and it changed its color from slightly brown to white according to its maturation stage and GSI was $1.41 \pm 0.19$. While for females, the ovaries became slightly swollen and orange /yellow in color. The GSI was $0.74 \pm 1.04$.

At the microscopical level, the testis consists of seminiferous lobules separated by thin connective stroma, radiating from the main sperm duct. All developmental stages of male germ cell could be observed. Spermatogonia $(13.3 \mu \mathrm{m} \pm 1.02)$ are found in the peripheral lobules whereas cysts packed with spermatozoa $(1 \mu \mathrm{m} \pm 0.92)$ lying free in the lobular lumen, occurred in the middle part of the testis (Fig. 1).

In control females, oocytes were observed to be in different maturity stages. They were oriented throughout the entire gonad. Developmentally, younger oocytes (oogonia) predominate at the periphery of the lamellae, whereas maturing cells locate centrally. Early perinucleolus oocytes measure $33.3 \pm 2.5 \mu \mathrm{m}$ and the cytoplasm is basophilic. A large, round nucleus is seen to lie centrally. The diameter of the nucleus (dk) is about $60 \%$ of the total oocyte diameter with a number of smaller nucleoli (7) situated peripherally. Late perinucleolus oocytes measure $52.4 \pm 1.25 \mu \mathrm{m}$ and the $\mathrm{dk}$ is about $50 \%$. The nucleus is still round in shape with a smooth surface with small and round nucleoli (11) which are found in the periphery of the nucleus (Fig. 2a \& table 2).

The chromatin nucleolus stage (synaptic stage) measures 12.3 $\pm 0.11 \mu \mathrm{m}$ and the cytoplasm is seen as a very narrow, weekly basophilic zone around the nucleus. The $\mathrm{dk}$ is about $75 \%$ containing a single nucleolus (Fig. 2b). 


\section{II-Effect of decreasing salinity:}

\section{1-At salinity $25 \%$ :}

After one month, on exposure to this level of salinity the testes were observed to be highly reduced in size and were smaller than control ones, having a white color. The testes seemed to be atrophied. The average GSI was $0.14 \pm 0.31$.

The histological structure of all testes appeared to contain only spermatogonia $(7.6 \pm 0.11 \mu \mathrm{m})$ among which small clusters of residual spermatozoa $(1 \mu \mathrm{m})$ seldom occur, and present in the sperm duct (Fig. 3).

Examination of some males about the first of November, which died after short period (one week), revealed that the germ cells detected in the testes were only spermatogonia $(7.5 \pm 0.69 \mu \mathrm{m})$ and a few nests of primary spermatocytes $(5.6 \pm 0.42 \mu \mathrm{m})$ (stage II). The mean GSI was 0.38 \pm 0.24 (Fig. 4).

Exposure to this level of salinity (25\%) for a long period appeared to have a retarding effect on the spermatogenesis activities.

For females the ovaries shrank and reduced in size and seemed to be translucent like spent stage and the mean GSI was $0.32 \pm 1.7$. Histological examination of ovaries showed beginning of degeneration of both early and late perinucleolus oocytes which are observed to have lost their uniform shape and their number, on the other hand showed a marked decrease. Oocytes diameters are smaller than control ones $(10.2 \pm 0.11 \&$ $30 \pm 0.13 \mu \mathrm{m}$ respectively) (table 2 ), this is coincidence with the shrinkage of the nucleus size. The cytoplasm also changed and differentiated in some oocytes into two layers and exhibit light stain (eosinophilic cell) with irregular cell membrane (Fig.5a). However, some oocytes are observed to be hypertrophied slightly and cell membrane was seen to be thick (Fig.5b). 
Inspection of some section through this level of salinity, some ovaries reveal the presence of a group of male germ cells which are called (spermatogonia-like cells) (SLCs) either at the periphery of lamella or in the midst of degenerating area of oocytes. These cells contained mild deeply staining nuclei, (1-2 um in diameter) and light-stain cytoplasm. The cluster of SLCS is considered to be the earliest reliable morphological sign of testicular development and is used as the key criterion for early sex reversal (Fig.6 a \& b).

\section{2-At salinity $16 \%$ :}

Fishes exposed to this level of salinity for about one month appeared to be slightly affected. Macroscopically, gonads were slightly reduced in size. Testes were creamy-white in color, having a smooth texture.

Microscopically, in the vast majority of cases, the testes examined show an active wave of spermatogenesis, indicated by the presence of spermatocytes, spermatids and seminiferous lobules, highly distended with spermatozoa. The sperm duct was also distended with spermatozoa. The Spermatogonia are faintly stained and are as usual peripheral. The diameter of both spermatogonia and spermatozoa did not differ from those in control ones ( $13.3 \pm 0.8 \& 1 \mu \mathrm{m}$ respectively). The mean GSI is small $(0.80 \pm 0.87)$ compared with control testes (Fig.7).

The ovaries of the fishes were observed to be slightly smaller than the control ones and the average was GSI $0.62 \pm 1.3$. The ovaries seemed to be translucent. Histological examination revealed that the diameters of both early and late perinucleolus oocytes are smaller than those found in control ovaries, $(28.3 \pm 0.27 \& 47.6 \pm 1.23 \mu \mathrm{m}$ respectively, table 2$)$. Their nucleus are spherical having about 11 nucleoli distributed on the margin of the nucleus (mean diameter $4 \mu \mathrm{m}$ ) (Fig. 8). 
The histological structure of some specimens indicate the presence of hermaphrodite fish, as the gonads appeared to consist of both ovarian and testicular tissues, the latter of which is functional (mean GSI 0.57 \pm 0.41 ). It consists of seminiferous lobules packed with spermatozoa and separated by thin connective stroma, while the ovarian portion showed non-oogenic activity, with degenerated follicles and the ovarian wall appeared to be thick. Those criteria are adopted as the key for early reversal male as well as early ripening of the fish exposed to this salinity (Fig. 9).

Generally, the testes examined about the first of November showed (after 25 days of exposure to this low level of salinity) varying degree of distention with spermatozoa and the first running male was detected.

\section{III-Effect of increasing salinity.}

\section{1-At salinity $40 \%$ :}

By the end of the experiment period the gonads were translucent, thin cylindrical and reduced in size, it seemed to be in immature stage. The GSI values for both males and females were $0.11 \pm 0.42$ and 0.4 \pm 0.67 respectively.

Histological examinations of testes show a complete degeneration of spermatogonia and inhibition of spermatogenesis activity. These are indicated by the presence of a lot number of degenerated spermatogonia, the lobules are not bound by any layer of connective tissue and few spermatozoa were spread between the spermatogonia (Fig.10).

In ovary section, the oocytes appeared to be collapsed. Their diameter decreased $(14.2 \pm 1.92 \mu \mathrm{m})$. The nucleus shrank markedly in size $(4.24 \pm 0.74 \mu \mathrm{m})$, no chromatin net or nucloeli are observed. Abnormalities in these oocytes are found: the cytoplasm is not homogeneous and compact compared with normal ovaries, abnormal development of small vacuoles all over the oocytes which form a spongy- looking cytoplasm whereas in normal ones these vacuoles extend to cover the cortical region 
of the cytoplasm which is faintly basophilic. The epithelial follicular membrane became thick (Fig.11 and table 2).

\section{2-At salinity $\mathbf{4 8} \%$ :}

Before beginning of this experiment, the male was in ripe stage where milt was extruded.

Fishes exposed to this level of salinity died after four days and the testes were markedly reduced in size and became extraordinary small (average weight $0.03 \mathrm{gm}$. and the total length was $16.5 \mathrm{~cm}$.) and the mean GSI was $0.05 \pm 0.64$.

The histological structure of the testes cleared that the sperm duct still contains sperms and few amounts of spermatozoa spread through the degenerated spermatogonia and signs of hypertrophy of the wall of lobules and deformation of the seminiferous lobules themselves (Fig.12a). Atrophy of the testes was followed. The testicular tissues showed definite signs of degeneration with spermatogonia, being actively phagocytosed by leukocytes (Fig. 12 b).

The female's gonads were pink in color and markedly reduced in size (average weight $0.06 \mathrm{gm}$., total length $16.4 \mathrm{~cm}$ ) and seemed to be immature stage. The GSI value was $0.20 \pm 0.94$. The histology structure of these ovaries revealed that females exposed to this level of salinity (48\%) seemed to have deleterious effect on the oocytes as rupture of late perinucleolar oocytes, increasing in the numbers of atretic follicles and degenerated cells were observed. (Fig.13).

\section{DISCUSSION}

The present study is an attempt to demonstrate the effect of salinity on the reproduction of Diplodus vulgaris during its breeding season which extends from November to January with a peak of spawning activity in December and January (Wassef, 1973 and Abdellah, 1996). 
The results of this study indicate that macroscopically, the gonads of fishes range from 15 to $17.5 \mathrm{~cm}$. total length (age I and II Wassef, 1973) exposed to $16 \%$ salinity were slightly reduced in size. The histological peculiarities of the testes of Diplodus vulgaris show active spermatogenesis (in November) indicated by the presence of the distension of both seminiferous lobules and sperm duct with spermatozoa (i.e. ripe male). Thus, contrary to what reported for the same species (Abdellah 1996), in which the spermatozoa were initially detected in some of examined testes in November. While for females the present study shows that the oogenic activity is characterized only by the presence of early and late perinucleolus oocytes.

At salinity $16 \%$, the average GSI $(0.80$ and 0.62$)$ for males and females respectively were smaller than at ambient salinity $(1.41 \& 0.74)$ and those reported by Wassef (1973) and Abdellah (1996) for the same species.

It is obvious that the male of Diplodus vulgaris reached ripe stage earlier at this level of salinity (16\%) than the control ones which attained ripe stage at December and January (Wassef, 1973 and Abdellah, 1996). Similar result was obtained by Kuo et.al. (1979), who succeeded to get mature males and females Chonas chonas exposed to $12 \%$ salinity.

In most sparids that have been studied, gonadal tissue differentiates as ovo-testis. Histological examination of gonadal development in Diplodus vulgaris confirmed that this species is a rudimentary hermaphrodite. Similar observation was reported by D'Ancon (1950) for the same species. Rudimentary hermaphroditism appear to be common reproductive style amongst African sparids and has been reported in a number of species of Sparodon durbanesis (Buxton and Garratt 1990), Pachymetopon grande (Buxton and Clarke, 1991) and Diplodus cervinus hottentotus (Mann and Buxton, 1998). It was obvious that the functional part of the ovo-testis was the testicular portion which 
appeared to ripen early as their seminiferous lobules were distended with spermatozoa.

Female fishes exposed to the same salinity $(16 \%)$ indicate that the ovaries contained early and late prinucleolus oocytes with slightly decreasing diameter $(47.6 \mu \mathrm{m})$. This is in a good agreement with Abd elBaki (1993) who reported that the salinity of about 15\% slightly affected the oocytes diameter of Liza ramada, but higher than this level the oocytes diameter decreased significantly.

In some fishes, sex inversion is induced or modified by environmental factors (Chan and Yeung, 1983; Shapiro, 1986). This is clear in the present results where early sex reversal was observed in some ovaries, that indicated by the presence of spermatogonia like cells (Fig. 6). Similar observations have been reported for the same species by Bonnet (1969) who suggested a probability of sex reversal phenomenon may be noticed in Diplodus vulgaris and he also stated that the appearance of trans-sexual cells within the primary gonad tissue of either sex is due to transformation of these cells from the original sex to other. In this case, sex reversal may have a profound effect on the sex structure and the proportion of fish undergoing female-to-male sex inversion might vary significantly from year to year.

From the morphological study of the fish subjected to $25 \%$, it was clear that their testes were extraordinary small and also the GSI values (0.14) were smaller than those at $16 \%$ (0.80). The testes became atrophied. Microscopically, the testes showed that most of spermatozoa seemed to be squeezed from cysts and degenerated spermatogonia were observed. From these observations, it can be concluded that at this salinity (25\%) spermatogenesis activity was inhibited.

The fishes exposed to hyper-saline media, their gonads showed great changes. A marked decrease in the gonad weight was observed. The GSI values were very small compared with the control ones. 
Histological examination of fishes exposed to $40 \%$ showed that the testes of Diplodus vulgaris suffered from cessation of spermatogenesis activities. In females, a marked reduction and shrinking of both ooctyes and their nuclei diameter beside the thickening of the follicular membrane were observed. Abnormalities were found in the oocyte in which small vacuoles developed all over the oocytes and the collapse of the oocytes indicated that the osmotic concentration at this degree of salinity is beyond the osmoregulatory capability of $D$. vulgaris oocytes.

The exposure to $48 \%$ salinity was observed to have caused the most deleterious effect on gonads of Diplodus vulgaris. A marked reduction of gonad weight and GSI values was noticed. The major processes affected might include degeneration of spermatogonia and inhibition of cell division. In females complete hypertrophy of ovaries, rupture of oocytes and degeneration of maturing follicles were observed.

On the contrary, gonad maturation of both males and females milkfish Chanos chanos were reported under a hyper-salinity and natural spawning was also reported (Kuo et al, , 1979; and Crear, 1980). Lee (1985) concluded that salinity is not critical for gametogenesis for the same species.

Several authors studied the effects of salinity on early life stages of teleosts (Holiday, 1965; May, 1974; Alderdice, 1988; Tandler et al., 1995).

Very few studies have dealt with the effect of exposure to different salinities on the gonadal development of marine fishes. However, studies which have concerned with euryhaline species showed that variations in salinities do not pose a barrier to induction of final maturation and spawning in Mugil cephalus, however they recommended $100 \%$ seawater for use during the spawning phase (Lee et al., 1992). It seems likely that such factors affected gametogenesis and spawning in Diplodus vulgaris. 
Generally, it could be inferred that histological examination of the gonads of Diplodus vulgaris after exposure to different degrees of salinity revealed that $16 \%$ to be the most suitable for complete gonadal maturation of this species.

\section{Acknowledgments}

The author wishes to thank Dr.S.Rizkallah and Professor W. Wadie for their critical comments on the manuscript.

\section{REFERENCES}

Abdellah, M.A. (1996). Reproductive biology and physiology of Diplodus vulgaris in the Mediterranean Sea Ph.D. Thesis, Fac. Sci. Tanta Univ.s234 pp.

Abd el Baki , Z. (1993). Effect of some environmental and physiological characteristics on reproduction of Liza ramada in Egypt. Msc. Thesis, Instit. Grad.. Studi. \& Res. Alex. Univ.,203pp.

Alderdice, D.F. (1988). Osmotic and ionic regulation in teleost egg and larvae. In Fish Physiology., . « XI A:1613-251.

Ashan, S.N. (1966). Effect of temperature and light on the cyclic changes in the spermatogenic activity of the lake chub, Couesius plumbeus. Can. J. Zool.,44:161-171.

Atz, J.W. (1964). Intersexuality in fishes. In: Intersexuality in Vertebrates. Armstrong C.N. \& A.J. Marshall, (edits), pp. 145-232 London: Academic Press.

Bennett, B.A., (1993). Aspect of the biology and life history of white steenbras Lithognathus lithognathus in southern Africa. S. Afr. J. Mar. Sci., 13: 83-93.

Breton, B. and Billard, R. (1977). Effects of photoperiod and temperature on plasma gonadotropin and spermatogenesis in rainbow trout 
Salmo gairdneri. Annls. Biol. Anim. Biochem. Biophy, 17 : 331340.

Bonnet, M. (1969). Les Sparides des cotes Nord-Quest Africaines. Rev.Trav.Inst. Peche.mar. 1: 97-116.

Buxton, C.D. (1990). The reproductive biology of Chrysoblephus laticeps and C. cristiceps (Teleostei: Sparidae). J. Zool. Lond., 220:497511.

Buxton, C.D., and Clarke, J.R. (1991). The biology of the white mussel cracker Sparodon dubanensis (Pisces: Sparidae) on the Eastern Cape coast, South Africa. S. Afr. J. Mar. Sci., 10: 285-296.

Buxton, C.D., and Clarke, J.R. (1992). The biology of the bronz bream, Pachymetopon grand (Teleostei: Sparidae) from the southeast Cape coast. S. Afr. J. Zool, 27: 21-32.

Buxton, C.D., and Garatt, P.A. (1990). Alternative reproductive style in seabream (Pisces: Sparidae). Env.Biol. Fish, 28: 113-124.

Bye,V.J. (1984). The role of environmental factors in the timing of reproductive cycles. In Fish Reproduction G.W.Potts \& R.J. Wootton, (eitds), pp 187-205. London Academic Press.

Chan, S. T.H., and Yeung, W.S. B. (1983). Sex control and sex reversal in fish under natural condition. In Fish Physiology.Vol. IX B W. S. Hoar; D. J.Randall \& E.M. Donaldson (edits), pp. 171-222 Academic. Press: New York.

Crear, D. (1980). Observations on the reproductive state of milkfish population Chanos chanos frpm hyper-saline ponds on Christmas Island (Pacific Ocean). Proc.World Maricul. Soc.,11: 548-556.

Crim, L.W. (1982). Environmental modulation of annual and daily rhythms associated with reproduction in teleost fishes. Can. J. Fish. Aquat. Sci.s 39: 17-21. 
D'Anocona, U. (1950). Determination et differnciation du sex chez les poissons. Arch. Anat. Microscop. Morphol.Exptl.,39: 274-299.

de Vlaming, V.L. (1972). Environmental control of teleost reproductive cycle: a brief review. J. Fish. Biol.,4:131-140.

Guraya, S.S., Kaur, R. and Saxena, p.k. (1975). Morphology of ovarian changes during the reproductive cycle of the fish, Mystus tengara, Ham. Acta. Anta., 91:222-260.

Holiday, F.G.T. (1965). Osmoregulation in marine teleosts egg and larvae. Cal.Coop. Oc.Fish.Inv., 10: 89-95.

Kuo, C.M., Nash, C.E., and Watanabe, W.D. (1979). Induced breeding experiments with milkfish Chanos chanos . Aquacul. 18: 95-105.

Lam, T.J. (1983). Environmental influences on gonadal activity in fish. In Fish Physiology. Vol. IX B W. S. Hoar \& D. J.Randall (edits), pp. 65-116. London Academic Press.

Lee, C.S. (1985). Environmental factors in the reproduction of milkfish Chanos chanos. The proc. Tungang Mari. Labor., 99-114

Lee, C.S.; Tmaru, C.S.; Kelley, C.D.; Moriwak, A. and Miyamot, G.T. (1992). The effect of salinity on the induction of spawning and of fertilization in striped mullet Mugil cephlaus. Aquacult, 102: 289296.

Mann, B.Q. and Buxton, C.D., (1998). The reproductive biology of Diplodus sargus capensis and D. cervinus hottentotus (Sparidae) off the South-east cap coast, South Africa. Cypium, 22: 31-47.

Matsuyama, M.; Lara, R.T. and Matsuura, S. (1988). Juvenile bisexuality in the red seabream, Pagrus major. Env.Biol.Fish, 21: 27-36.

May, R.C. (1974). Effects of temperature and salinity on yolk utilization in Bairdiella icistiia (Pisces: Scianidae). J. Exp. Biol. Ecol., 16: 213-370. 
Reinboth, R. (1970). Intersexuality in fishes.Mem. Soc Endocr., 18: 515543.

Stacey, N.E. (1984). Control of the timing of ovulation by exogenous and endogenous factors. In Fish Reproduction G.W.Potts \& R.J. Wootton, (edits), pp 207-222. London Academic Press.

Tanddler, A., Anav, F. A., and Choshniak, I. (1995). The effect of salinity on growth rate, survival and swimbladder inflation in gilthead seabream, Sparus aurata, larvae. Aquacult, 135: 343-353.

Tortonese, E. (1965). Biolgie comparée de trois espèces méditerranénnes de Diplodus (Pisces: Sparidae). Rapp.et Proc.Verb.C.I.F.S.M., Monaco,18: 189-192.

West, G. (1990). Methods of assessing ovarian development in fishes: a review. Aust. J. Mar.Freshwater Res. ,41:199-222.

Wassef, E.A. (1973). Study on the biology of Genus Diplodus (Sargus) and related species of the family Sparidae in Mediterranean. M.Sc. Thesis, Fac. Sci. Alex. Univ., 215pp.

Yamamoto, K. (1956). Studies on the formation of fish eggs. I. Annual cycle in the development of the ovarian eggs in the flounder, Liposetta obscura. J.Fac. Sci. Hokkaido Univ.g; 12:362-373. 
Table (1): Measurement of salinity, temperature. oxygen and $\mathrm{pH}$ in the experimental tanks.

\begin{tabular}{|c|c|c|c|c|}
\hline Tank N0. & $\begin{array}{c}\text { Salinity } \\
\%\end{array}$ & $\begin{array}{c}\text { Temperature } \\
\mathrm{Tc}^{\circ}\end{array}$ & $\begin{array}{c}\text { Oxygen } \\
\text { O2 mg/l }\end{array}$ & $\mathrm{pH}$ \\
\hline 1 (Control) & 36 & 24.3 & 3.8 & 8.57 \\
\hline 2 & 25 & 24.5 & 4.2 & 8.81 \\
\hline 3 & 16 & 24.2 & 4 & 8.85 \\
\hline 4 & 40 & 24.2 & 4.1 & 8.81 \\
\hline 5 & 48 & 24.2 & 4.1 & 8.75 \\
\hline
\end{tabular}

Table (2): Diameter ( \pm s.e) of oocytes and GSI ( \pm s.e) values of females Diplodus migaris at different salinity levels.

\begin{tabular}{|c|lc|c|}
\hline Salinity\%o & \multicolumn{2}{|l|}{ Diameter of oocyles( $\mathrm{mm})$} & GSI \\
& E.p & L.p & \\
\hline 36 & $33.3 \pm 2.50$ & $52.4 \pm 1.25$ & $0.74 \pm 1.0 \mathrm{t}$ \\
\hline 25 & $10.2 \pm 0.11$ & $30 \pm 0.13$ & $0.32 \pm 1.7$ \\
\hline 16 & $28.3 \pm 0.27$ & $47.6 \pm 1.23$ & $0.62 \pm 1.3$ \\
\hline 40 & - & $14.2 \pm 1.92$ & $0.40 \pm 0.67$ \\
\hline $48^{*}$ & - & - & $0.2 \pm 0.94$ \\
\hline
\end{tabular}

*No diameter of oocytes at this level of salinity were obtained that were suitable for measurement, due to the ruptured and atretic oocytes.

- Early and late perimucleolus. 
Fig.(1). Part of T.S. from testis of control male Diplodus vulgaris $(16.8 \mathrm{~cm}$ T.L $G S I=1.14$ ). Mary mature spermatozoa occur in the central part. Seminiferous lobules contain all spermatogenic stages; $X 360$.

Fig.(2). a-Part of T.S. from ovary of control female Diplodus vulgaris ( $I 7.1 \mathrm{~cm}$ T.L $G S I=0.74)$. Early and late perimiclelous oocyte; $X 360$.

b- chromatin macleolus stage (synaptic stage) from the same specimen viewed ander high magnification $(X 900)$.

Fig. (3). Part of T.S. from testis of male Dilpodus vulgaris (17.8cm T.L, GSI=0.14) at salinity 25\%, showing reduced testis, undetectable radial character of seminiferous lobules and spermatogonia predominating; $X 90$.

Fig. (4). Part of T.S. from testis of male Diplodus vulgaris (I4.5cm T.L. (GSI=0.38) at salinity $25 \%$, died after one week showing rare nests of primary spermatocytes which are visible among spermatogonia; $X 360$.

Fig.(5). a- Part of T.S. from ovary of female Diplodus vulgaris (I8.5 cm T.L, (iSI $=0.32$ ) at salinity $25 \%$. The beginming of elegeneration and the oocytes losit their wniform shape having light stain of cytoplasm; $X 225$.

$b$ - Hyperatrophy of some oocytes at the same salinity; $X 225$.

Fig.(6). a- Part of T.S. from ovary of female Diplodus vulgaris (15.1 cm T.L, ( $i S I=0.53)$ showing the early-sex reversing at salinity 25\%. Arrow shows small chuster of "sprmatogonial-like cells"SLCSX 360.

$b$ - The cluster of SLC's ander high magnification; $X 900$.

Fig. (7). Pari of T.S. from Jesris of ripe male Diplodus vulgaris $(16.4 \mathrm{~cm}$ T.L (iS)=-

$0.8)$ af salinity /6\%; showing active spermatogensis, predominating spermatozoa, $X 360$. 
Fig.(8). Part of T.S. from ovary of female Diplodus vulgaris (16.I cm T.L,

$(G S I=0.62)$ at salinity $16 \%$, showing oocytes which slightly reduced in size; $X 225$.

Fig. (9). Part of T.S. from hermaphrodite gonads of Diplodus vulgaris (15.2 cm T.L, $G S I=0.57)$ at salinity $16 \%$, showing spawning male and degenerating follicles. The lobules distend with spermatozoa; $X 225$.

Fig. (10). Part of T.S. from testis of Diplodus vulgaris (16cm T.L, GSI=0.1I) at salinity $40 \%$. Degeneration of spermatogonia and undetectable lobules $X 225$.

Fig.(11). Part of T.S. from ovary of female Diplodus vulgaris (18.5cm T.L, GSI=0.40) at salinity $40 \%$, showing the abnormalities of both cytoplasm and formation of the vacuoles; $X 360$.

Fig.(12). a- Part of T.S. from testis of Diplodus vulgaris (16.4cm T.L, GSI=0.05) at salinity $48 \%$, showing degeneration of spermatogonia and deformation of lobules; $X 360$.

$b$ - section of degenerated testicular tissue from the same specimen viewed under high magnification, showing the phagocytosed spermatogonia $X 900$.

Fig.(1.3). Part of T.S' from ovary of female Diplodus vulgaris (I6.5 cm T.L, (is'I $=0.20)$ at salinity $48 \%$, showing the muture of the oocytes and increasing of atretic follicles; $X 225$.

\section{Abbreviations:}

at = ateritic oocytes, $\quad \mathrm{cm}=\mathrm{cell}$ membrane, $\quad(N S=$ chromatin macleohs stage, \& $c y=c y l o p) l a s m$,

$D=$ degenerated area, do = degenerated oocyte, $D O=$ degenerated ovary

DSS $G=$ degenerated spermatogonia., ep= early perimicleohs oocyte.

$I=$ leucocytes, $I p=$ late perinucleolus oocyte, $N=$ micleus and.

()$V^{\prime}=$ ovary, $\left.S I\right)=$ sperm duct, $S(j=$ spermatogonia, sp=spermayocytes and $s=$ spermalozoct, $\quad T=$ testis. 

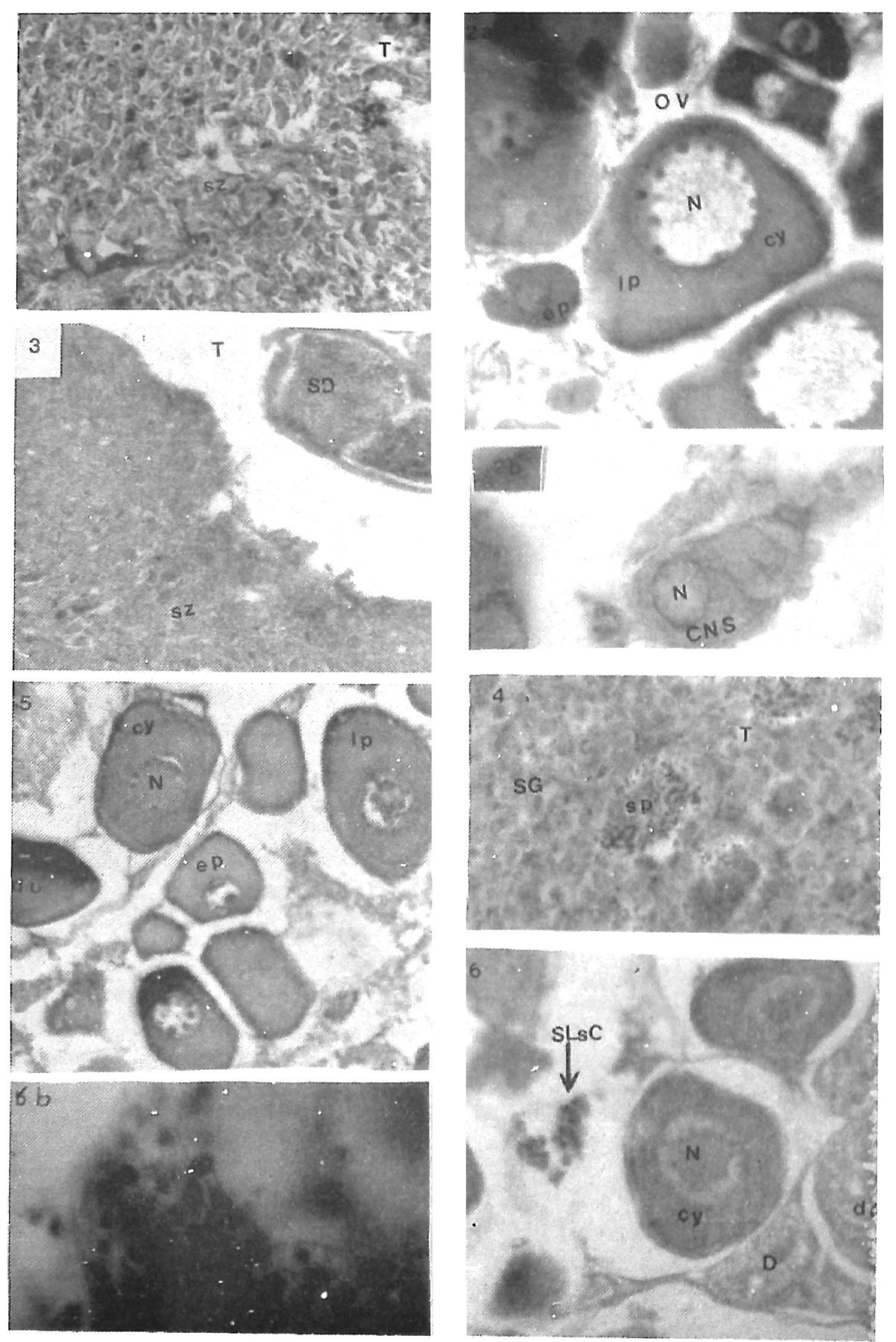

